\title{
Supporting Information: Metal Sheet of Atomic Thickness Embedded in Silicon
}

\author{
Leonid V. Bondarenko ${ }^{1}$, Alexandra Y. Tupchaya ${ }^{1}$, Yurii E. Vekovshinin ${ }^{1,2}$, \\ Dimitry V. Gruznev ${ }^{1}$, Alexey N. Mihalyuk ${ }^{1,2}$, Dmitry A. Olyanich ${ }^{1}$, Yurii P. Ivanov ${ }^{1,2,3}$, \\ Andrey V. Matetskiy ${ }^{1}$, Andrey V. Zotov ${ }^{1}$ and Alexander A. Saranin ${ }^{1, *}$ \\ ${ }^{1}$ Institute of Automation and Control Processes FEB RAS, \\ 5 Radio Street, 690041 Vladivostok, Russia \\ ${ }^{2}$ School of Natural Sciences, Far Eastern Federal University, \\ 690950 Vladivostok, Russia \\ ${ }^{3}$ Department of Materials Science and Metallurgy, \\ University of Cambridge, Cambridge CB3 0FS, UK
}

November 12, 2021

\section{Delta-Layers in Silicon: Historical Background}

For fabrication of the delta-layers in silicon, boron (B) has been sofar used as the $p$-type dopant and antimony ( $\mathrm{Sb}$ ) and phosphorus $(\mathrm{P})$ as the $n$-type dopants. Extensive researches on Si:B and Si:Sb delta-layers date back to the 1990s. General approach used in those works was based in preparation of a given surface reconstruction on silicon, which incorporates up to a monolayer (ML) of dopant atoms $\left(1.0\right.$ ML equals $7.8 \times 10^{14} \mathrm{~cm}^{-2}$ and $6.8 \times 10^{14} \mathrm{~cm}^{-2}$ for $\mathrm{Si}(111)$ and $\mathrm{Si}(100)$ substrate orientations, respectively) as a template, and capping it with a silicon film using either low-temperature molecular-beam epitaxy (LT-MBE: Si deposition onto the sample heated to the modest temperatures) or solid-phase epitaxy (SPE: amorphous $\mathrm{Si}$ (a-Si) deposition onto the sample held at room temperature (RT) followed by annealing to induce epitaxial recrystallization of the Si film).

In particular, using a $\mathrm{Sb} / \mathrm{Si}(100) 2 \times 1$ reconstruction, the $\mathrm{Si}(100)$ :Sb delta-layers were grown with electron sheet concentration $n^{2 D} \sim 2.5 \times 10^{14} \mathrm{~cm}^{-2}$ and mobility $\mu_{n} \sim 40 \mathrm{~cm}^{2} / \mathrm{V} \mathrm{s}$ $[1,2]$. Possibility for growing delta-doping $\operatorname{Si}(100)$ :Sb superlattices $(\delta$-i- $\delta$-i-superlattices $)$ was also demonstrated [2-4]. The dopant activation in the heavily-doped $\mathrm{Si}(100)$ :Sb delta-layer was about $50 \%$ [2]. For the $\mathrm{Si}(111)$ :Sb delta-layers, it appeared to be an order of magnitude lower and the maximal electron concentration achieved there was only $\sim 0.4 \times 10^{14} \mathrm{~cm}^{-2}$ [5], though the template $\mathrm{Sb} / \mathrm{Si}(111)$ reconstructions (i.e., $\sqrt{3} \times \sqrt{3}, 2 \times 1,5 \sqrt{3} \times 5 \sqrt{3}$ [6-9]) demonstrate a sufficiently higher structural ordering than the $\mathrm{Sb} / \mathrm{Si}(100) 2 \times 1$ one [10-12].

As for the boron-doped delta-layers, their formation on $\mathrm{Si}(111)$ substrate attracted especial attention. Boron was found to form the highly-ordered $\mathrm{B} / \mathrm{Si}(111) \sqrt{3} \times \sqrt{3}$ recon-

\footnotetext{
${ }^{*}$ Corresponding author
} 
struction at 1/3 ML B coverage [13-15] and its atomic arrangement was conclusively determined to consist of $\mathrm{B}$ atoms residing in the fivefold-coordinated substitutional site below a Si adatom at a $T_{4}$ site [16-20]. The fact that $\mathrm{B}$ atoms already occupy the Si lattice sites below the surface showed a promise that upon subsequent Si overgrowth they would remain in their sites and demonstrate high electrical activation. Indeed, upon RT deposition of amorphous $\mathrm{Si}$, the $\sqrt{3} \times \sqrt{3}$ reconstruction is preserved at the buried a-Si/Si $(111)$ interface [21-25]. Such samples show $p^{2 D} \sim 2.0 \times 10^{14} \mathrm{~cm}^{-2}$ and $\mu_{p} \sim 30 \mathrm{~cm}^{2} / \mathrm{V} \mathrm{s}$. However, epitaxial crystallization of the a-Si film requires heating to $\sim 500^{\circ} \mathrm{C}$ which destroys the buried reconstruction and leads to the profile smearing [26]. Interesting peculiarities of epitaxial Si overgrowth on $\mathrm{B} / \mathrm{Si}(111)$ surface are the two-bilayer Si island formation at the early stages of LT-MBE growth [26-30] and the twinned (180 rotated) orientation of the grown $\mathrm{Si}$ film relative to the $\mathrm{Si}(111)$ substrate $[27,28,31-33]$, that, in particular, allows the growth of Si twinning superlattice [34].

The B-adsorbed $\mathrm{Si}(100)$ surface adopts $0.5 \mathrm{ML}$ of $\mathrm{B}$. According to scanning tunneling microscopy $(\mathrm{STM})$ observations, the $\mathrm{B} / \mathrm{Si}(100)$ surface is heterogeneous with patches of superstructures having various local periodicities [35-38]. A number of structural models were proposed for them [37,39-45], but their reliable confirmation is still lacking. Epitaxial $\mathrm{Si}$ growth on $\mathrm{Si}(100)$ substrate occurs at temperatures by $\sim 300^{\circ} \mathrm{C}$ lower, than those for growth on $\mathrm{Si}(111)$ substrate, that facilitates the sharp $\operatorname{Si}(100)$ :B delta-layer formation. It was established that in order to avoid B segregation the LT-MBE should be conducted at temperatures below $\sim 230^{\circ} \mathrm{C}$ and $\mathrm{SPE}$ regrowth at temperatures below $\sim 500^{\circ} \mathrm{C}[42,46]$. Even upon LT-MBE growth at $300^{\circ} \mathrm{C}, \sim 50 \%$ of $\mathrm{B}$ remains in the the ordered sites and $\mathrm{B}$ spreading is $\sim 0.5 \mathrm{~nm}[23,24,47]$. The $\operatorname{Si}(100)$ :B delta-layers show $p^{2 D} \sim 3.0 \times 10^{14} \mathrm{~cm}^{-2}$ and $\mu_{p} \sim 20-40 \mathrm{~cm}^{2} / \mathrm{V}$ s $[48,49]$.

The recent renewed research activity in growing and characterization of the delta-layers in silicon has been associated with using phosphorus, as a dopant. In the experiments, the atomically-clean $\mathrm{Si}(100) 2 \times 1$ surfaces were saturation dosed with phosphine $\left(\mathrm{PH}_{3}\right)$ at RT and briefly annealed to substitutionally incorporate $\mathrm{P}$ atoms into the top $\mathrm{Si}(100)$ layer and to remove hydrogen and, finally, capped by Si film using LT-MBE at $\sim 250^{\circ} \mathrm{C}[50$ $52]$. Using this technique, the high electron concentrations $\left(n^{2 D} \sim 2.4 \times 10^{14} \mathrm{~cm}^{-2}\right.$ [50] with $\mu_{n} \sim 35 \mathrm{~cm}^{2} / \mathrm{V} \mathrm{s}$ [53]) were achieved. However, the actual sharpness of the $\mathrm{Si}(100): \mathrm{P}$ deltalayer (especially from the Si film side) causes certain doubts, since the sample resistance was reported to drop rapidly with increasing thickness of a Si capping film, that was explained in terms of dopant segregation during encapsulation [52].

Thus, it can be concluded that the known techniques for fabrication of the delta-layers in silicon allow to achieve the high sheet concentrations of carriers up to $\sim 3.0 \times 10^{14} \mathrm{~cm}^{-2}$ and mobilities of $\sim 20-40 \mathrm{~cm}^{2} / \mathrm{V} \mathrm{s}$, which are higher (albeit being of the same order) than the values for the uniformly doped Si films, if one compares them with the short-period $\delta$-i- $\delta$-i-superlattices. The goal that was not definitely reached is the controlled confinement of the delta-layer within a single atomic plane. 


\section{In Situ STM-LEED-XPS-ARPES Characterization of Si Growth on $\mathrm{Tl} / \mathrm{NiSi}_{2} / \mathrm{Si}(111)$}

Experimental results on RT Si overgrowth onto the Tl-capped single-layer $\mathrm{NiSi}_{2}$ on $\mathrm{Si}(111)$ are summarized in Figures 1S and 2S. In particular, Figures 1S(a-d) illustrate evolution of the sample surface structure and morphology showing STM images and LEED patterns recorded after deposition of 2.5, 5.0, 13.0 and 38.0 ML of Si. One can see that at the early growth stage (at $2.5 \mathrm{ML}$ ) the surface is covered by islands with a flat top and their prevailed thickness was found to correspond to that of the two $\operatorname{Si}(111)$ bilayers, $0.628 \mathrm{~nm}$. Remind that similar two-bilayer islands were observed at LT-MBE Si growth on B/Si(111) surface [26-30]. Thus, one can assume that such behavior might be a common feature of $\mathrm{Si}$ epitaxy on the chemically inert $\mathrm{Si}(111)$ surfaces. The difference of the presence case from that with a $\mathrm{B} / \mathrm{Si}(111)$ surface is that the epitaxial $\mathrm{Si}$ growth occurs here already at RT without any heating of the sample. The sample with $2.5 \mathrm{ML}$ of Si displays a sharp and bright $1 \times 1$ LEED pattern (Fig. $1 \mathrm{~S}(\mathrm{a})$ ). The sharp $1 \times 1$ LEED pattern remains after deposition of 5.0 ML of Si (Fig. 1S (b)), but then LEED reflections fade with Si deposition: their faint traces are still seen after deposition of 13.0 ML of Si (Fig. 1S (c)) and disappear completely after deposition of 38.0 ML of Si (Fig. 1S (d)). Corresponding set of the STM images also reflects degradation of the film crystalline structure: the film surface becomes gradually more rough and featureless.

Figure 1S (e) shows XPS spectra from the bare $\mathrm{Tl} / \mathrm{NiSi}_{2} / \mathrm{Si}(111)$ surface (shown by the black curve) and after deposition of $38 \mathrm{ML}$ (i.e., $\sim 6.0 \mathrm{~nm}$ ) of Si onto it (shown by the red curve). From comparison of the two spectra, one can see that upon Si deposition the intensity of the Ni $3 p$ peak drops to zero, while the Tl $4 f$ peak preserves $\sim 70 \%$ of its initial intensity.

Figure $2 \mathrm{~S}$ presents ARPES spectra recorded from the pristine $\mathrm{Tl} / \mathrm{NiSi}_{2} / \mathrm{Si}(111)$ sample and after deposition of 2.5, 5.0 and 13.0 ML of Si onto it. To facilitate analysis of the experimental spectra, Figures 3S ( $\mathrm{a}, \mathrm{b}$ ) show calculated electronic band structures for the $\mathrm{Tl} / \mathrm{NiSi}_{2} / \mathrm{Si}(111)$ and $\mathrm{Tl} / \mathrm{Si}(111)$ samples, respectively. In particular, one can see that before Si deposition ARPES spectrum displays exclusively the features associated with a single-layer $\mathrm{NiSi}_{2}$ sandwiched between monolayer $\mathrm{Tl}$ and $\mathrm{Si}(111)$ substrate (Fig. 2S (a) and Fig. 3S (a)). After deposition of 2.5 ML of Si (Fig. 2S (b)), the $\mathrm{NiSi}_{2}$ features remain, while the new feature appears, namely, a band with a flat top centered in the $\Gamma$ point. This is a clear signature of the $\mathrm{Tl} / \mathrm{Si}(111) 1 \times 1$ surface reconstruction [54,55] (Fig. 3S (b)). After deposition of 5.0 ML of Si (Fig. 2S (c)), all the features remain but become blurred and after deposition of 13.0 ML of Si (Fig. 2S (d)), their traces are hardly resolved, indicating formation of the disordered amorphous film.

Basing on the obtained results, one can make the conclusions, as follows.

- Single-layer $\mathrm{NiSi}_{2}$ is preserved at the buried interface.

- Most of Tl atoms segregate to a surface of a growing Si film.

- Si film adjacent to the buried $\mathrm{NiSi}_{2}$ is crystalline (epitaxial), but its structure degrades towards amorphous with increasing distance from the $\mathrm{NiSi}_{2}$ delta-layer.

All these conclusions receive a clear and solid confirmation from the results of the HAADF HRSTEM observations (see the main text). 


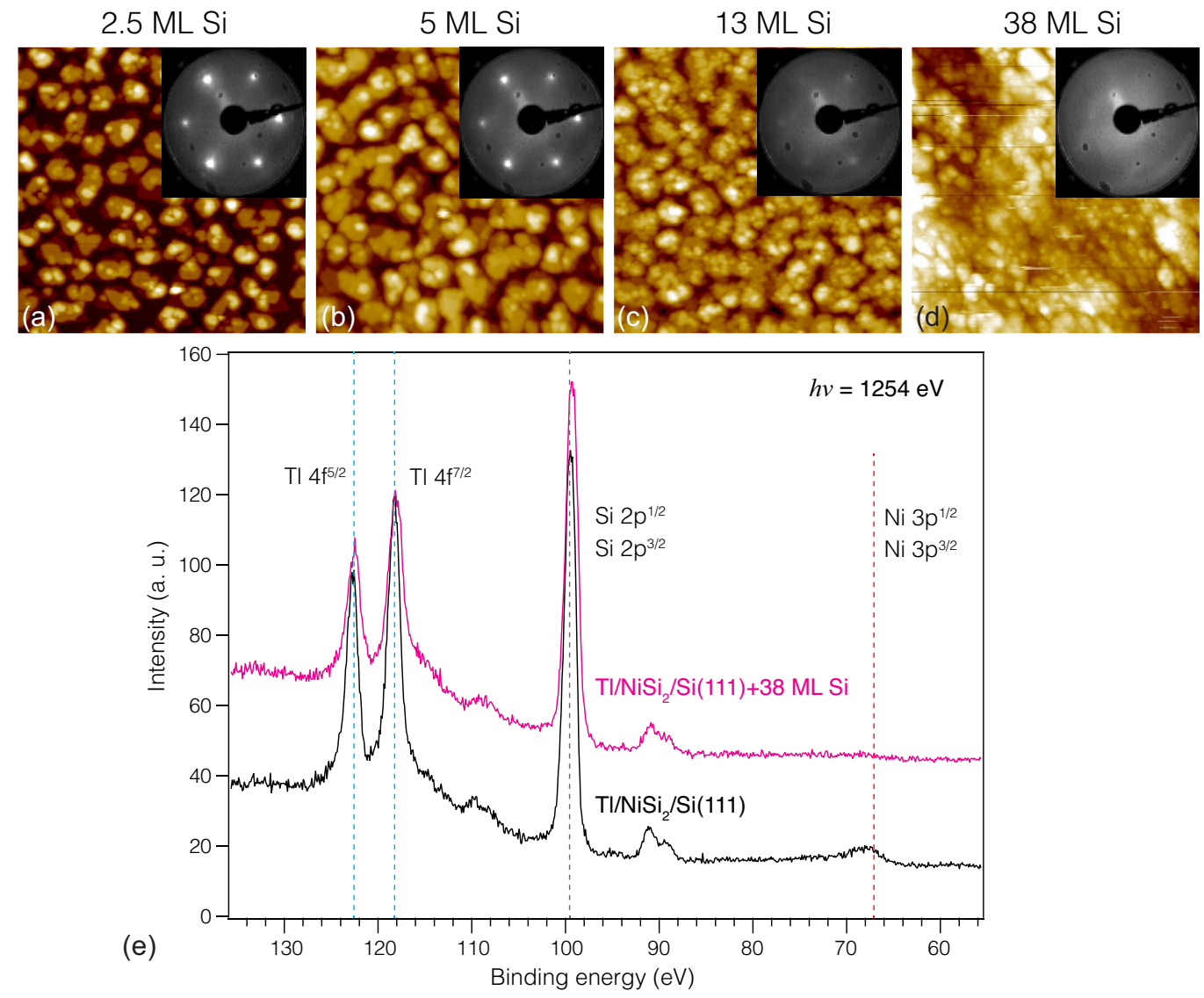

Figure 1S: Experimental LEED-STM-XPS data on the RT $\mathrm{Si}$ overgrowth on $\mathrm{Tl} / \mathrm{NiSi}_{2} / \mathrm{Si}(111)$. A set of LEED patterns $\left(E_{p}=60 \mathrm{eV}\right)$ and $100 \times 100 \mathrm{~nm}^{2} \mathrm{STM}$ images of the $\mathrm{Tl} / \mathrm{NiSi}_{2} / \mathrm{Si}(111$ ) surface after deposition of (a) 2.5, (b) 5.0, (c) $13.0 \mathrm{ML}$ and (d) 38.0 ML of Si. (e) XPS spectra $(h \nu=1254.6 \mathrm{eV})$ from the bare $\mathrm{Tl} / \mathrm{NiSi}_{2} / \mathrm{Si}(111)$ surface (black curve) and after overgrowth of 38.0 ML of Si onto it (red curve). 


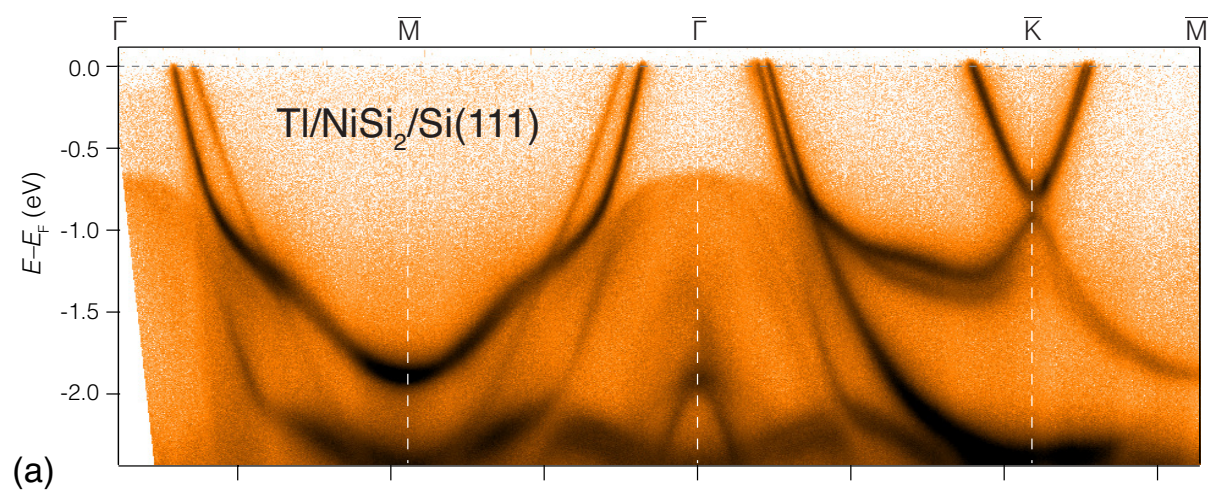

(a)

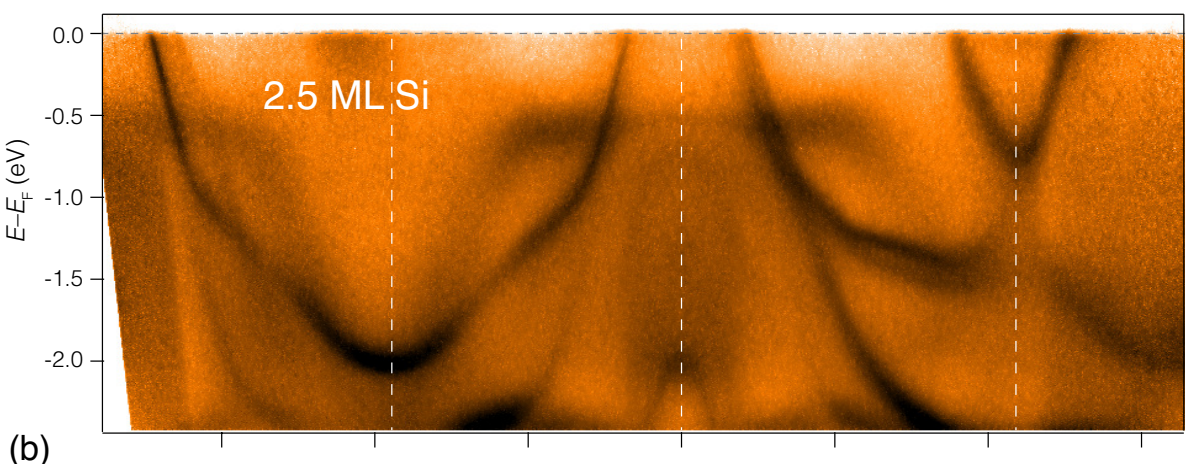

(b)
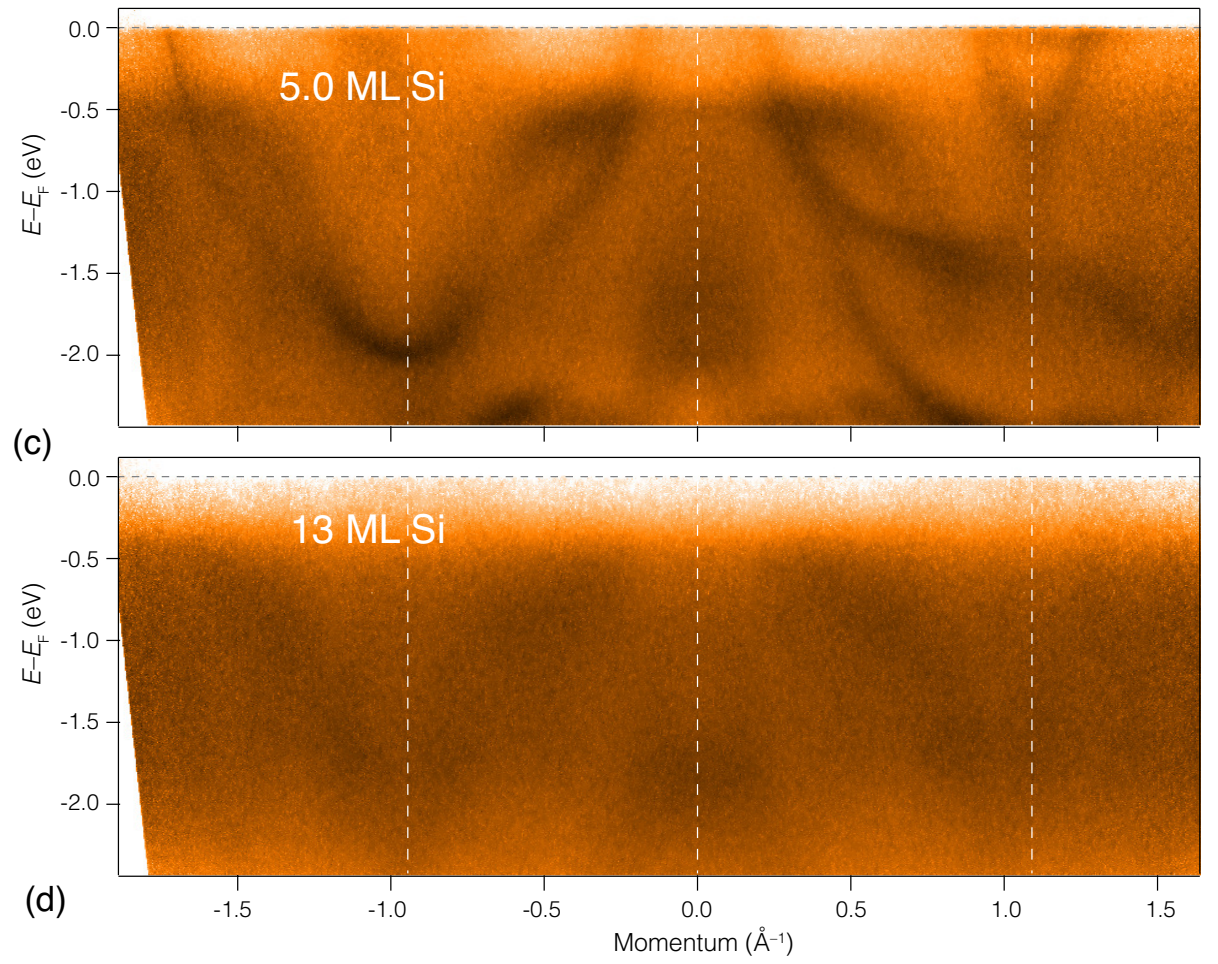

Figure 2S: Experimental ARPES spectra from (a) the bare $\mathrm{Tl} / \mathrm{NiSi}_{2} / \mathrm{Si}(111)$ surface and after RT deposition of (b) 2.5, (c) 5.0 and (d) 13 ML of Si onto it. 

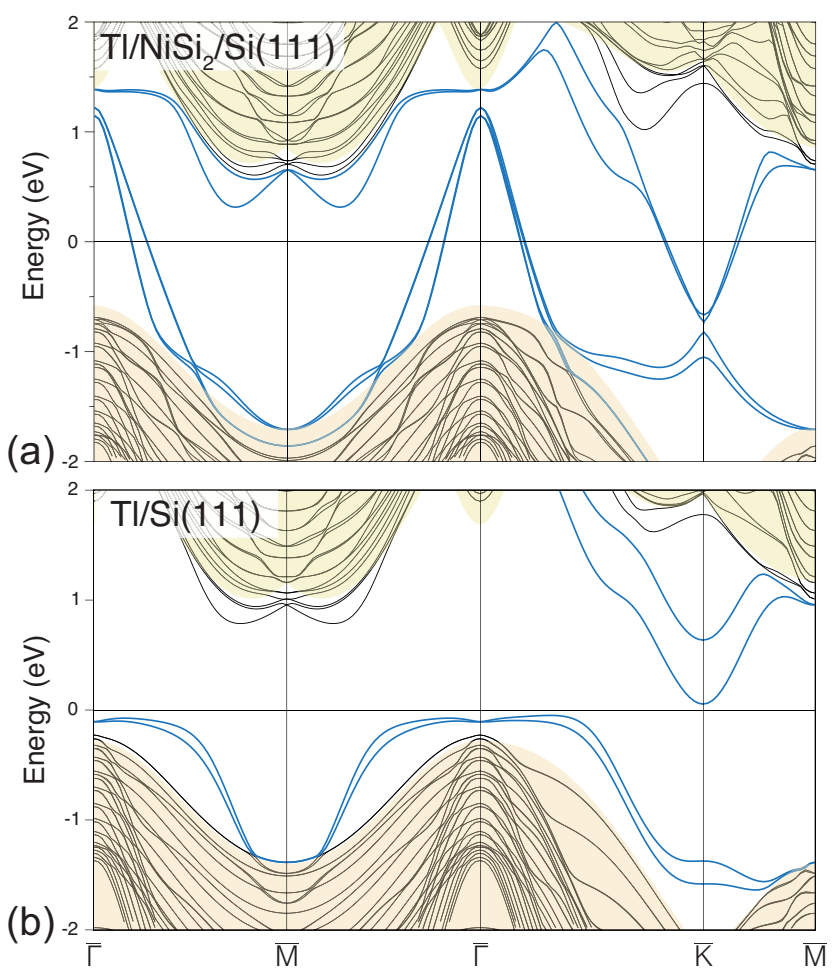

Figure 3S: Calculated electronic band structures for (a) Tl/ $\mathrm{NiSi}_{2} / \mathrm{Si}(111)$ (b) $\mathrm{Tl} / \mathrm{Si}(111)$ surfaces using the calculation slab containing $10 \mathrm{Si}(111)$ bi-layers. Shaded gray regions indicate projected bulk bands. 


\section{Chemical Analysis of the $\mathrm{NiSi}_{2}$ Delta-Layer Structure Using HAADF HRSTEM and STEM EDX}

It is generally known that the contrast of HAADF STEM images is sensitive to the compositional changes [56]. The scattered intensity from an atomic column scales with the mean atomic number $Z$. For the thin enough objects, it is often assumed that the scattered intensity scales with $Z^{n}$, where $n$ is a constant which depends on the HAADF detector geometry and might depend also on the sample thickness, crystal structure and crystal orientation. Calibration experiments for our samples yielded $n \sim 0.9$. Though the absolute quantification of chemical composition from HAADF STEM data is a complicated task, the relative quantification is possible. Composition of the unknown columns can be evaluated by comparing the corresponding peak intensity with the intensity of the known columns. Figure 4S (a) shows a raw HAADF STEM image. To improve the signal-to-noise ratio for the quantitative analysis, we applied a lattice-enhanced filter to the original image [57]. The filtered HAADF STEM image is shown on the Fig. 4S (b). Figures 4S (c) and (d) show intensity profiles along the corresponding dashed lines in Fig. 4S (b). As one can see, the maximum intensity of the profile passing through the metallic atomic column (red) is 1.75 times greater than the maximum intensity of the Si columns (green). Bearing in mind that $Z(\mathrm{Ni})=28$ is twice greater than $Z(\mathrm{Si})=14$, the metallic columns plausibly consist of $\mathrm{Ni}$, rather than $\mathrm{Tl}$ with $Z(\mathrm{Tl})=81$.
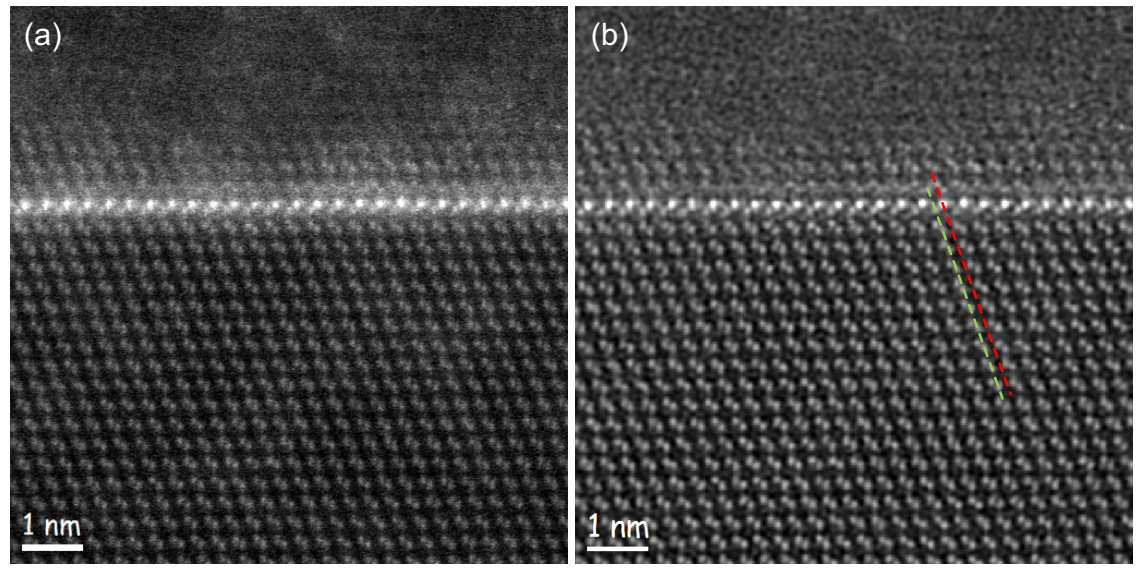

(c)

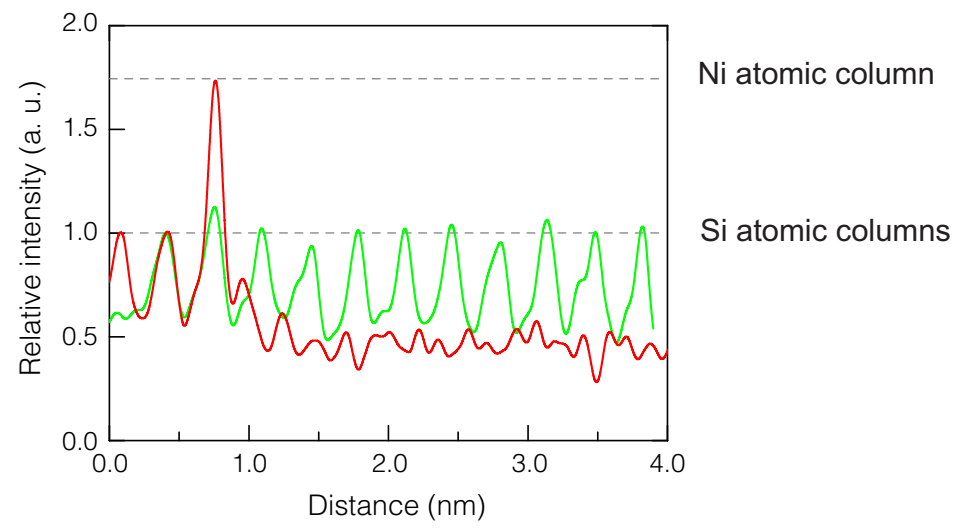

Figure 4S: (a) Raw and (b) filtered HAADF STEM images of the $\mathrm{NiSi}_{2}$ delta-layer embedded in the crystalline Si. (c) Intensity profiles across the delta-layer along the corresponding dashed lines indicated in (b). 
Finally, we performed the energy-dispersive X-ray (EDX) spectroscopic analysis. Figure $5 \mathrm{~S}$ shows the HAADF STEM image and corresponding chemical map for $\mathrm{Si}, \mathrm{Ni}$ and $\mathrm{Pt}$ (protective coating). Though the technique is lacking atomic resolution, the map clearly shows that $\mathrm{Ni}$ is localized only in the $\mathrm{NiSi}_{2}$ delta-layer. Moreover, the averaged EDX spectrum (0.5 nm width) extracted from the $\mathrm{NiSi}_{2}$ delta-layer contains only $\mathrm{Si}$ and $\mathrm{Ni}$ peaks without any sign of $\mathrm{Tl}$ (i.e., at $2.267 \mathrm{keV}(\mathrm{Tl} \mathrm{M})$ and $10.267 \mathrm{keV}\left(\mathrm{Tl} \mathrm{L}_{\alpha}\right)$ ).
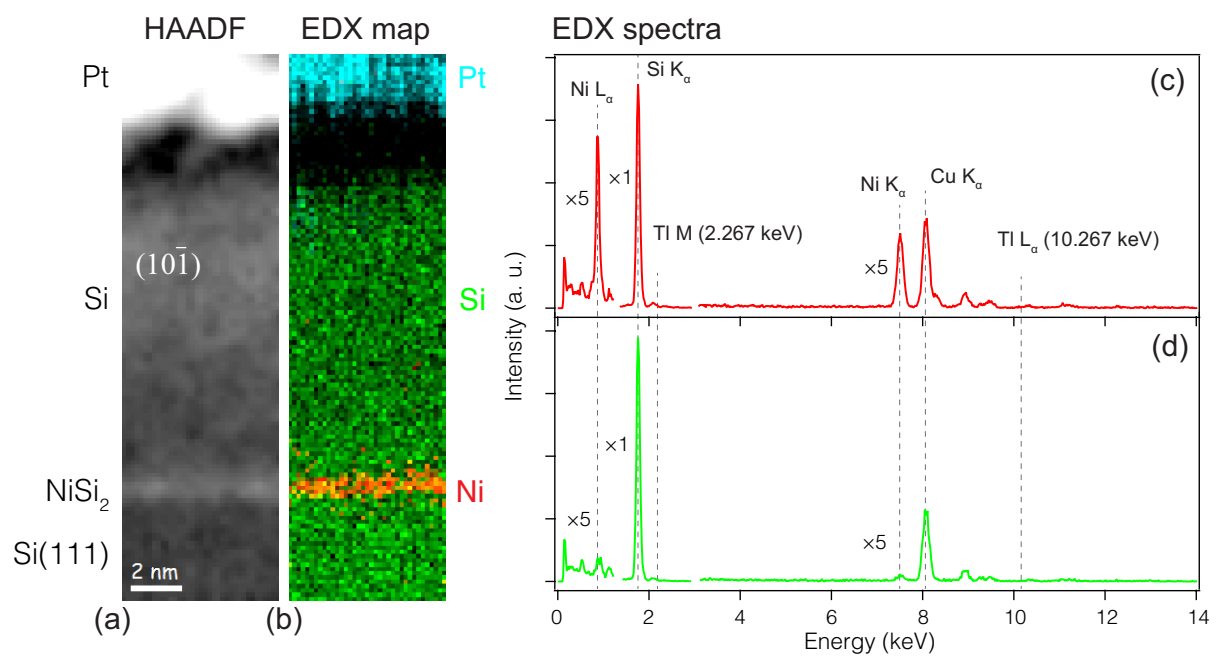

Figure 5S: (a) HAADF STEM image, (b) corresponding EDX chemical map for Ni (red), $\mathrm{Si}$ (green) and $\mathrm{Pt}$ (blue), and the averaged EDX spectra taken from (c) the $\mathrm{NiSi}_{2}$ delta-layer and (d) Si substrate. The EDX signal intensity is multiplied by five in the energy regions below 1.5 and above $3.0 \mathrm{keV}$. The positions of the $\mathrm{Ni}, \mathrm{Si}, \mathrm{Cu}, \mathrm{Tl}$ peaks in the spectra are indicated by the vertical dashed lines. The $\mathrm{Cu}$ peak is due to the TEM cooper grid holding the sample. 


\section{Atomic Structure of the Buried $\mathrm{Si} / \mathrm{NiSi}_{2} / \mathrm{Si}(111)$ Interface}

High-resolution TEM images of the buried $\mathrm{Si} / \mathrm{NiSi}_{2} / \mathrm{Si}(111)$ interface with a cross-section

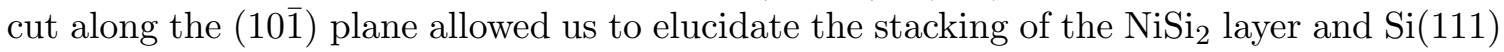
bi-layers. Figure $6 \mathrm{~S}$ presents comparison of the ball-and-stick models with the results of the HAADF HRSTEM observations. Bearing in mind that $\mathrm{NiSi}_{2}$ films on $\mathrm{Si}(111)$ can occur in the two possible orientations, A-type (Si lattice planes continue through the interface) and B-type $\left(180^{\circ}\right.$ rotated), we constructed the models where the $\mathrm{NiSi}_{2}$ layer has either A-type (Fig. 6S (b)) or B-type (Fig. 6S (c)) interfaces with the lower ( $\mathrm{Si}(111)$ substrate) and upper (capping film) Si layers. One can see that none of these models fits the TEM results. The proper model (labelled as C-type) is that presented in Fig. $6 \mathrm{~S}(\mathrm{~d})$, where the $\mathrm{NiSi}_{2}$ is in the B-type orientation with respect to the underlying $\mathrm{Si}(111)$ substrate, but has an unusual stacking with the capping Si layer, as its Si atoms are bonded to the Ni atoms, but not to $\mathrm{Si}$ atoms as at the A- or B-type interfaces.

DFT calculations showed that among three models the most energetically favorable is that with the A-type interfaces (Fig. $6 \mathrm{~S}$ (b)), the most unstable (by $\sim 120 \mathrm{meV}$ with respect to the A-type model) is that with the B-type interfaces (Fig. 6S (c)). The C-type model (Fig. 6S (d)) shows an intermediate stability being less stable than the A-type model by $\sim 10$ to $100 \mathrm{meV}$, depending on the pseudopotentials used in calculations. Since the original $\mathrm{NiSi}_{2} / \mathrm{Si}(111)$ interface before $\mathrm{Si}$ overgrowth is in the B-type orientation, the C-type model is realized, but not the lowest-energy A-type, since the former does not require large atomic reordering that would occur in the course of reconstructing the $\mathrm{NiSi}_{2} / \mathrm{Si}(111)$ interface from the $\mathrm{B}$ - to A-type. The C-type interface is metastable: It can withstand a heating to $\sim 100^{\circ} \mathrm{C}$, but becomes destroyed upon heating to $\sim 300^{\circ} \mathrm{C}$.
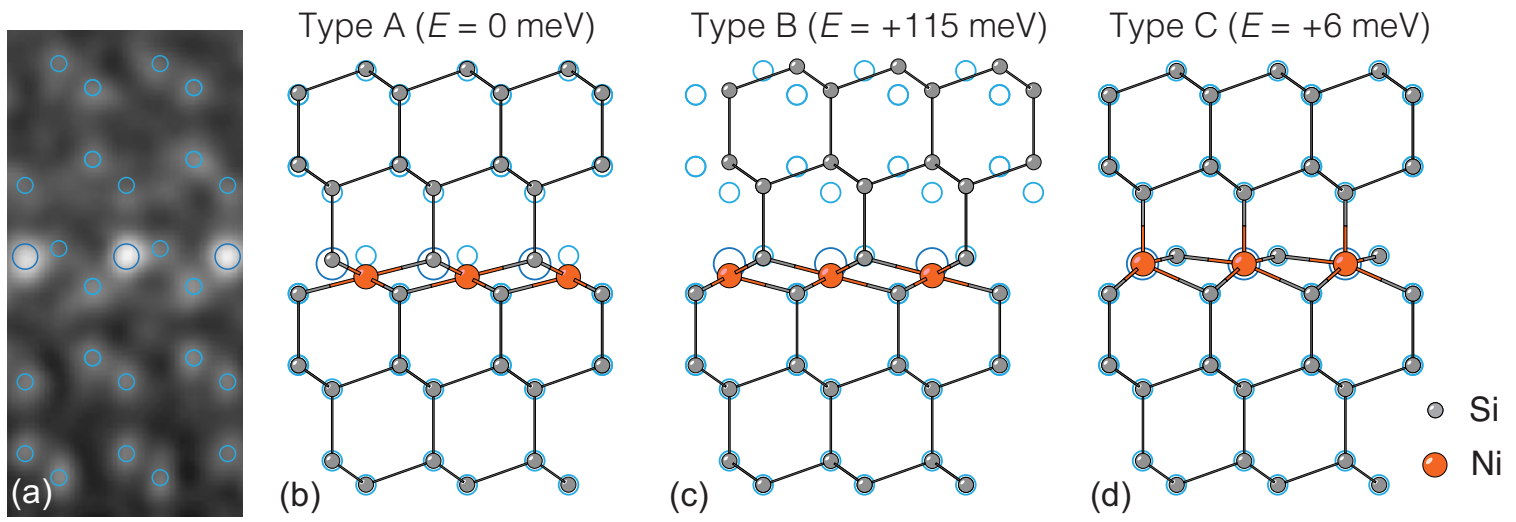

Figure 6S: (a) Cross-sectional TEM view of the buried $\mathrm{Si} / \mathrm{NiSi}_{2} / \mathrm{Si}(111)$ interface along the (101) plane with Si atoms highlighted by small blue circles and Ni atoms by large blue circles. Calculated ball-and-stick models of the buried $\mathrm{Si} / \mathrm{NiSi}_{2} / \mathrm{Si}(111)$ interface having (b) A-type, (c) B-type and (d) C-type structures. The models are superposed with schematics showing locations of $\mathrm{Ni}$ and $\mathrm{Si}$ atoms as in (a). Ni atoms are shown by red balls and $\mathrm{Si}$ atoms by gray balls. 


\section{Physical Quantities Characterizing the Electronic and Trans- port Properties of the $\mathrm{NiSi}_{2}$ Delta-Layer}

Table 1: Physical quantities, Fermi vector $k_{\mathrm{F}}$, effective mass $m^{*}$, Fermi velocity $v_{\mathrm{F}}$, elastic scattering time $\tau_{e}$, mobility $\mu$ and carrier concentration $n$ for the S1 and S2 hole bands and S3 electron band evaluated from the comparison of the calculated band structure and transport measurements.

\begin{tabular}{lllccccc}
\hline Band & Carriers & $k_{\mathrm{F}}\left[\AA^{-1}\right]$ & $\mathrm{m}^{*}$ & $v_{\mathrm{F}}\left[10^{8} \mathrm{~cm} / \mathrm{s}\right]$ & $\tau_{e}$ fs & $\mu\left[\mathrm{cm}^{2} / \mathrm{V} \cdot \mathrm{s}\right]$ & $n\left[10^{14} \mathrm{~cm}^{-2}\right]$ \\
\hline S1 & holes & 0.191 & 0.203 & 0.787 & 14.0 & 122 & 0.548 \\
S2 & holes & 0.228 & 0.303 & 0.626 & 17.6 & 102 & 1.049 \\
S3 & electrons & 0.056 & 0.467 & 0.139 & 79.1 & 273 & 0.110 \\
\hline
\end{tabular}




\section{WAL Effect in the $\mathrm{NiSi}_{2}$ Delta-Layer}

Figure 7S presents the results of the transport measurements in magnetic field. The data set includes sample conductivity measured with magnetic field varied from -1.0 to $+1.0 \mathrm{~T}$ and sample temperature being held at 1.5, 3.0, 6.0, 12.024 .0 and $32.0 \mathrm{~K}$. The sign of the conductance variation and shape of the curves indicate occurrence of the weak antilocalization effect, which can be described in the framework of the Hikami-Larkin-Nagaoka (HLN) theory [58] as:

$$
\Delta \sigma(B)=\frac{\alpha e^{2}}{2 \pi^{2} \hbar}\left[\ln \frac{B_{\phi}}{B}-\psi\left(\frac{1}{2}+\frac{B_{\phi}}{B}\right)\right]
$$

where, $\psi$ is the digamma function, the characteristic field $B_{\phi}=\hbar / 4 e l_{\phi}^{2}, l_{\phi}$ is dephasing length and $\hbar$ is the Planck's constant. According to the HLN theory, coefficient $\alpha$ equals -0.5 for the WAL in the 2D systems. However, experimental values of $\alpha$ often deviate from -0.5 and might vary with film thickness [59,60], electron concentration [61] and temperature $[59,60,62-65]$. By applying equation (1) to the experimental curves, the fitting parameters of $l_{\phi}$ and $\alpha$ can be evaluated as a function of temperature. In particular, $\alpha$ appears to grow with temperature from -0.15 at $1.5 \mathrm{~K}$ to -0.10 at $32 \mathrm{~K}$, following the trend already detected in some material systems $[60,64,65]$. The dephasing length decreases from $\sim 100 \mathrm{~nm}$ at $1.5 \mathrm{~K}$ to $\sim 30 \mathrm{~nm}$ at $32.0 \mathrm{~K}$. It is worth noting, however, that application of formulae (1) is based on a very simple assumption that all carriers are of the same type, that is apparently not fulfilled in the present system. Because of oversimplified assumption, the gained estimates are fairly crude, pending a more complicated analysis incorporating the knowledge on the system electronic band structure.

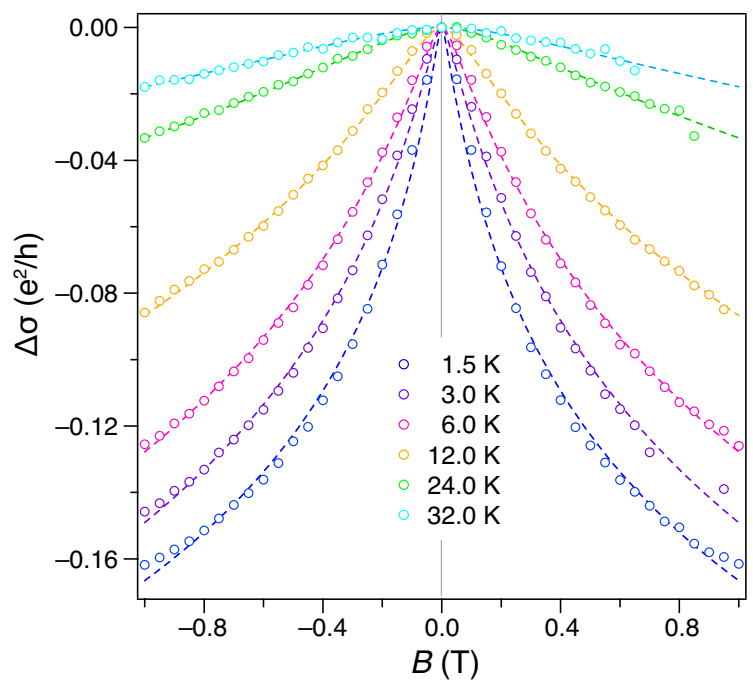

Figure 7S: (a) Magnetoconductivity of the $\mathrm{NiSi}_{2}$ delta-layer structure measured in the field varied from -1.0 to $+1.0 \mathrm{~T}$ and at sample temperatures of 1.5, 3.0, 6.0, 12.024 .0 and 32.0 $\mathrm{K}$ shown by open circles of various colors. The dashed lines of the corresponding color represent theoretical fitting curves based on the HLN theory. 


\section{References}

[1] W. X. Ni, G. V. Hansson, J. E. Sundgren, L. Hultman, L. R. Wallenberg, J. Y. Yao, L. C. Markert, J. E. Greene, Delta-Function-Shaped Sb-Doping Profiles in Si(100) Obtained Using a Low-Energy Accelerated-Ion Source during Molecular-Beam Epitaxy, Phys. Rev. B 46 (1992) 7551-7558.

[2] H. J. Gossmann, F. C. Unterwald, Dopant Electrical Activity and Majority-Carrier Mobility in B- and Sb- $\delta$-Doped Si Thin Films, Phys. Rev. B 47 (1993) 12618-12624.

[3] A. V. Zotov, A. A. Saranin, V. G. Lifshits, E. A. Khramtsova, Solid Phase Epitaxial Growth of Si on Si-Sb Surface Phases for the Formation of $\delta$-Doped Layers and $\delta-i-$ $\delta-i$-Superlattices, Surf. Sci. 230 (1990) L147-L150.

[4] I. Eisele, F. Wittmann, V. G. Lifshits, A. V. Zotov, Z. Z. Ditina, S. V. Ryzhkov, Transport Properties of Delta-Doped Si:Sb Superlattices, Thin Solid Films 238 (1994) $27-30$.

[5] A. V. Zotov, V. G. Lifshits, Z. Z. Ditina, P. A. Kalinin, Formation and Electrical Characterization of Buried Si(111)-Sb and Si(100)-Sb Surface Phases, Surf. Sci. 273 (1992) L453-L456.

[6] Y. J. Ko, K. H. Park, J. S. Ha, W. S. Yun, Atomic Structure of the Sb-Induced $\mathrm{Si}(111)-(5 \sqrt{3} \times 5 \sqrt{3}) R 30^{\circ}$ Surface: Ab Initio Calculations, Phys. Rev. B 59 (1999) $4588-4591$.

[7] A. A. Saranin, A. V. Zotov, V. G. Lifshits, O. Kubo, T. Harada, M. Katayama, K. Oura, Si(111) $5 \sqrt{3} \times 5 \sqrt{3}$-Sb: A Surface Phase with a Variable Composition, Surf. Sci. 447 (2000) 15-24.

[8] S. Bengió, M. Martin, J. Avila, M. C. Asensio, H. Ascolani, Atomic Structure of the Sb-Terminated Si(111) Surface: A Photoelectron Diffraction Study, Phys. Rev. B 65 (2002) 205326-7.

[9] K. Okamoto, K. Yoshimoto, Y. Sugawara, S. Morita, KPFM Imaging of $\mathrm{Si}(111) 5 \sqrt{3} \times 5 \sqrt{3}$-Sb Surface for Atom Distinction Using NC-AFM, Appl. Surf. Sci. 210 (2003) 128-133.

[10] A. A. Saranin, A. V. Zotov, V. G. Kotlyar, V. G. Lifshits, O. Kubo, T. Harada, T. Kobayashi, N. Yamaoka, M. Katayama, K. Oura, Surface Roughening at the OneMonolayer Sb/Si(100) Interface, Phys. Rev. B 65 (2002) 033312-4.

[11] P. De Padova, R. Larciprete, C. Quaresima, A. Reginelli, P. Perfetti, Temperature Effect on the Reconstruction of $\mathrm{Sb} / \mathrm{Si}(001)$ Interface Studied by High Resolution Core Level Spectroscopy and RHEED Analysis, Appl. Surf. Sci. 166 (2000) 214-219.

[12] M. Shimomura, T. Abukawa, K. Yoshimura, J. H. Oh, H. W. Yeom, S. Kono, Photoelectron Diffraction Study of the Si 2p Surface-Core-Level-Shift of the $\mathrm{Si}(001)(1 \times 2)-\mathrm{Sb}$ Surface, Surf. Sci. 493 (2001) 23-28.

[13] V. V. Korobtsov, V. G. Lifshits, A. V. Zotov, Formation of $\operatorname{Si}(111) \sqrt{3} \times \sqrt{3}-\mathrm{B}$ and $\mathrm{Si}$ Epitaxy on $\operatorname{Si}(111) \sqrt{3} \times \sqrt{3}-$ B: LEED-AES Study, Surf. Sci. 195 (1988) 466-474. 
[14] H. Hirayama, T. Tatsumi, N. Aizaki, Reflection High Energy Electron Diffraction and Auger Electron Spectroscopic Study on B/Si(111) Surfaces, Surf. Sci. 193 (1988) L47L52.

[15] P. Dumas, F. Thibaudau, F. Salvan, Scanning Tunnelling Microscopy of B/Si(111) $\sqrt{3} \times$ $\sqrt{3}-R\left(30^{\circ}\right)$, J. Microscopy 152 (1988) 751-759.

[16] I. W. Lyo, E. Kaxiras, P. Avouris, Adsorption of Boron on Si(111): Its Effect on Surface Electronic States and Reconstruction, Phys. Rev. Lett. 63 (1989) 1261-1264.

[17] H. Huang, S. Y. Tong, J. Quinn, F. Jona, Atomic Structure of $\operatorname{Si}(111)(\sqrt{3} \times \sqrt{3}) R 30-\mathrm{B}$ by Dynamical Low-Energy Electron Diffraction, Phys. Rev. B 41 (1990) 3276-3278.

[18] P. J. Bedrossian, R. D. Meade, K. Mortensen, D. M. Chen, J. A. Golovchenko, D. Vanderbilt, Surface Doping and Stabilization of Si(111) with Boron, Phys. Rev. Lett. 63 (1989) 1257-1260.

[19] R. L. Headrick, I. K. Robinson, E. Vlieg, L. C. Feldman, Structure Determination of Si(111): $\mathrm{B}(\sqrt{3} \times \sqrt{3}) R 30$ Surface. Subsurface Substitutional Doping, Phys. Rev. Lett. 63 (1989) 1253-1256.

[20] D. P. Andrade, R. H. Miwa, B. Drevniok, P. Drage, A. B. McLean, Surface and near Surface Defects in $\delta$-Doped Si(111), J. Phys.: Cond. Matt. 27 (2015) 125001-8.

[21] R. L. Headrick, L. C. Feldman, I. K. Robinson, Stability of Boron- and GalliumInduced Surface Structures on $\mathrm{Si}(111)$ During Deposition and Epitaxial Growth of Silicon, Appl. Phys. Lett. 55 (1989) 442-444.

[22] K. Akimoto, I. Hirosawa, T. Tatsumi, H. Hirayama, Structure of $(\sqrt{3} \times \sqrt{3}) R 30-\mathrm{B}$ at the Si Interface Studied by Grazing Incidence X-Ray Diffraction, Appl. Phys. Lett. 56 (1990) 1225-1227.

[23] R. L. Headrick, B. E. Weir, A. F. J. Levi, B. S. Freer, J. Bevk, L. C. Feldman, Ordered Monolayer Structures of Boron in $\mathrm{Si}(111)$ and $\mathrm{Si}(100)$, J. Vac. Sci. Technol. A 9 (1991) 2269-2272.

[24] R. L. Headrick, B. E. Weir, A. F. J. Levi, D. J. Eaglesham, L. C. Feldman, Buried, Ordered Structures: Boron in $\operatorname{Si}(111)$ and $\mathrm{Si}(100)$, J. Cryst. Growth 111 (1991) 838842.

[25] R. L. Headrick, A. F. J. Levi, H. S. Luftman, J. Kovalchick, L. C. Feldman, Electrical Conduction in the $\mathrm{Si}(111): \mathrm{B}-(\sqrt{3} \times \sqrt{3}) R 30 / \alpha-$ Si Interface Reconstruction, Phys. Rev. B 43 (1991) 14711-14714.

[26] A. V. Zotov, M. A. Kulakov, S. V. Ryzhkov, V. G. Lifshits, B. Bullemer, I. Eisele, Si Overgrowth on $\operatorname{Si}(111) \sqrt{3} \times \sqrt{3}-B$ Surface Phase, Surf. Sci. 352/354 (1996) 358-363.

[27] H. Hibino, K. Sumitomo, T. Ogino, Growth Process of Twinned Epitaxial Layers on $\operatorname{Si}(111) \sqrt{3} \times \sqrt{3}$-B and Their Thermal Stability, Appl. Surf. Sci. 130/132 (1998) 41-46.

[28] H. Hibino, T. Ogino, Formation of Twinned Two-Bilayer-High Islands during Initial Stages of Si Growth on $\operatorname{Si}(111) \sqrt{3} \times \sqrt{3}$-B, Surf. Sci. 412/413 (1998) 132-140. 
[29] A. Fissel, J. Krügener, H. J. Osten, Influence of Boron on the Initial Stages of Si Molecular Beam Epitaxy on Si(111) Studied by Reflection High-Energy Electron Diffraction, Surf. Sci. 603 (2009) 477-481.

[30] A. Fissel, J. Krügener, D. Schwendt, J. Osten, Role of Boron and $(\sqrt{3} \times \sqrt{3})$-B Surface Defects on the Growth Mode of $\mathrm{Si}$ on $\mathrm{Si}(111)$ : A Photoemission and Electron Diffraction, Phys. Status Solidi (a) 207 (2010) 245-253.

[31] R. L. Headrick, B. E. Weir, J. Bevk, B. S. Freer, D. J. Eaglesham, L. C. Feldman, Influence of Surface Reconstruction on the Orientation of Homoepitaxial Silicon Films, Phys. Rev. Lett. 65 (1990) 1128-1131.

[32] H. Hibino, T. Kawamura, T. Ogino, RHEED Analysis of Twinned Homoepitaxial Layers Grown on $\operatorname{Si}(111) \sqrt{3} \times \sqrt{3}$-B, Thin Solid Films 369 (2000) 5-9.

[33] H. Hibino, Y. Watanabe, Growth of Twinned Epitaxial Layers on $\operatorname{Si}(111) \sqrt{3} \times \sqrt{3}-\mathrm{B}$ Studied by Low-Energy Electron Microscopy, Jpn. J. Appl. Phys. 44 (2005) 358-364.

[34] H. Hibino, T. Ogino, Growth of Si Twinning Superlattice, Mat. Sci. Eng. B 87 (2001) $214-221$.

[35] Y. Wang, R. J. Hamers, E. Kaxiras, Atomic Structure and Bonding of Boron-Induced Reconstructions on Si(001), Phys. Rev. Lett. 74 (1995) 403-406.

[36] M. A. Kulakov, Z. Zhang, A. V. Zotov, B. Bullemer, I. Eisele, Structure of the B/Si(100) Surface at Low Boron Coverage Studied by Scanning Tunnelling Microscopy, Appl. Surf. Sci. 103 (1996) 443-450.

[37] T. Komeda, Y. Nishioka, Atomic Structure of Segregated Boron on Si(001) Surface: Scanning Tunnelling Microscopy and Cluster Model Calculation Study, Surf. Sci. 405 (1998) 38-45.

[38] H. Yan-fang, Y. Jian-shu, C. Qun, B-Induced Reconstruction on Si(100)-(2×1) Surface Studied with Scanning Tunneling Microscopy, Materials Characterization 48 (2002) $183-188$.

[39] J. Chang, M. J. Stott, Si(001)/B Surface Reconstruction, Phys. Rev. B 53 (1996) 13700-13704.

[40] M. Ramamoorthy, E. L. Briggs, J. Bernholc, Chemical and Strain Effects on BoronDoped Si(100), Phys. Rev. B 59 (1999) 4813-4821.

[41] V. G. Zavodinsky, I. A. Kuyanov, E. N. Chukurov, Computer Study of Boron Segregation at the $\operatorname{Si}(100)-2 \times 1$ and $\operatorname{Si}(111)-\sqrt{3} \times \sqrt{3}$ Surfaces, J. Vac. Sci. Technol. A 17 (1999) 2709-2712.

[42] Z. Zhang, M. A. Kulakov, B. Bullemer, I. Eisele, A. V. Zotov, B/Si(100) Surface: Atomic Structure and Epitaxial Si Overgrowth, J. Vac. Sci. Technol. B 14 (1996) $2684-2689$.

[43] J. Fritsch, J. B. Page, K. E. Schmidt, G. B. Adams, First-Principles Local-Orbital Study of the Boron-Induced Reconstruction of Si(001), Phys. Rev. B 57 (1998) 97459756. 
[44] Z. Liu, Z. Zhang, X. Zhu, Atomic Structures of Boron-Induced Protrusion Features on Si(100) Surfaces, Phys. Rev. B 77 (2008) 035322-5.

[45] A. Sweetman, S. Gangopadhyay, R. Danza, N. Berdunov, P. Moriarty, QPlus Atomic Force Microscopy of the Si(100) Surface: Buckled, Split-Off and Added Dimers, Appl. Phys. Lett. 95 (2009) 063112-3.

[46] Z. Zhang, M. A. Kulakov, B. Bullemer, I. Eisele, A. V. Zotov, Epitaxial Growth of Ultrathin Si Caps on Si(100):B Surface Studied by Scanning Tunneling Microscopy, Appl. Phys. Lett. 69 (1996) 494-496.

[47] B. E. Weir, D. J. Eaglesham, L. C. Feldman, H. S. Luftman, R. L. Headrick, Electron Microscopy of the Ordered Boron $2 \times 1$ Structure Buried in Crystalline Silicon, Appl. Surf. Sci. 84 (1995) 413-418.

[48] B. E. Weir, L. C. Feldman, D. Monroe, H. J. Gossmann, R. L. Headrick, T. R. Hart, Electrical Characterization of an Ultrahigh Concentration Boron Delta-Doping Layer, Appl. Phys. Lett. 65 (1994) 737-739.

[49] T. Suemasu, M. Yamamoto, K. Takakura, S. Hashimoto, Y. Kumagai, F. Hasegawa, Si Molecular Beam Epitaxial Growth Over an Atomic-Layer Boron Adsorbed Si(001) Substrate and Its Electrical Properties, Jpn. J. Appl. Phys. 36 (1997) 7146-7151.

[50] S. R. McKibbon, W. R. Clarke, A. Fuhrer, T. C. G. Reusch, M. Y. Simmons, Investigating the Regrowth Surface of Si:P $\Delta$-Layers towards Vertically Stacked Three Dimensional Devices, Appl. Phys. Lett. 95 (2009) 233111-3.

[51] C. M. Polley, W. R. Clarke, J. A. Miwa, M. Y. Simmons, J. W. Wells, Microscopic Four-Point-Probe Resistivity Measurements of Shallow, High Density Doping Layers in Silicon, Appl. Phys. Lett. 101 (2012) 262105-4.

[52] C. M. Polley, W. R. Clarke, J. A. Miwa, G. Scappucci, J. W. Wells, D. L. Laeger, M. R. Bischof, R. F. Reidy, B. P. Gorman, Exploring the Limits of $n$-Type UltraShallow Junction Formation, ACS Nano 7 (2013) 5499-5505.

[53] K. E. J. Goh, L. Oberbeck, M. Y. Simmons, A. R. Hamilton, M. J. Butcher, Influence of Doping Density on Electronic Transport in Degenerate Si:p $\delta$-Doped Layers, Phys. Rev. B 73 (2006) 025401-6.

[54] K. Sakamoto, T. Oda, A. Kimura, K. Miyamoto, M. Tsujikawa, A. Imai, N. Ueno, H. Namatame, M. Taniguchi, P. E. J. Eriksson, R. I. G. Uhrberg, Abrupt Rotation of the Rashba Spin to the Direction Perpendicular to the Surface, Phys. Rev. Lett. 102 (2009) 096805-4.

[55] D. V. Gruznev, L. V. Bondarenko, A. V. Matetskiy, A. A. Yakovlev, A. Y. Tupchaya, S. V. Eremeev, E. V. Chulkov, J. P. Chou, C. M. Wei, M. Y. Lai, Y. L. Wang, A. V. Zotov, A. A. Saranin, A Strategy to Create Spin-Split Metallic Bands on Silicon Using a Dense Alloy Layer, Sci. Rep. 4 (2014) 4742-5.

[56] C. B. Carter, D. B. Williams (Eds.), Transmission Electron Microscopy. Diffraction, Imaging, and Spectrometry, 1st Edition, Springer: Cham, 2016. doi:https://doi.org/10.1007/978-3-319-26651-0. 
[57] O. Krivanek, M. Chisholm, V. Nicolosi, T. Pennycook, G. Corbin, N. Dellby, M. Murfitt, C. Own, Z. Szilagyi, M. Oxley, S. Pantelides, S. Pennycook, Atom-by-Atom Structural and Chemical Analysis by Annular Dark-Field Electron Microscopy, Nature 464 (2010) 571-574.

[58] S. Hikami, A. I. Larkin, Y. Nagaoka, Spin-Orbit Interaction and Magnetoresistance in the Two Dimensional Random System, Progress of Theoretical Physics 62 (1980) $707-710$.

[59] Y. S. Kim, M. Brahlek, N. Bansal, E. Edrey, G. A. Kapilevich, K. Iida, M. Tanimura, Y. Horibe, S.-W. Cheong, S. Oh, Thickness-Dependent Bulk Properties and Weak Antilocalization Effect in Topological Insulator $\mathrm{Bi}_{2} \mathrm{Se}_{3}$, Phys. Rev. B 84 (2011) 073109.

[60] D. L. Mo, W. B. Wang, Q. Cai, Influence of Thickness on the Electrical Transport Properties of Exfoliated $\mathrm{Bi}_{2} \mathrm{Te}_{3}$ Ultrathin Films, Nanoscale Research Letters 11 (2016) 354.

[61] J. Chen, H. J. Qin, F. Yang, J. Liu, T. Guan, F. M. Qu, G. H. Zhang, J. R. Shi, X. C. Xie, C. L. Yang, K. H. Wu, Y. Q. Li, L. Lu, Gate-Voltage Control of Chemical Potential and Weak Antilocalization in $\mathrm{Bi}_{2} \mathrm{Se}_{3}$, Phys. Rev. Lett. 105 (2010) 176602.

[62] Z. Li, T. Chen, H. Pan, F. Song, B. Wang, J. Han, Y. Qin, X. Wang, R. Zhang, J. Wan, D. Xing, G. Wang, Two-Dimensional Universal Conductance Fluctuations and Electron-Phonon Interaction of Surface States in $\mathrm{Bi}_{2} \mathrm{Te}_{2} \mathrm{Se}$ Microflakes, Sci. Rep. 2 (2012) 595.

[63] L. Bao, L. He, N. Meyer, X. Kou, P. Zhang, Z. Chen, A. V. Fedorov, J. Zou, T. M. Riedemann, T. A. Lograsso, K. L. Wang, G. Tuttle, F. Xiu, Weak Anti-Localization and Quantum Oscillations of Surface States in Topological Insulator $\mathrm{Bi}_{2} \mathrm{Se}_{2} \mathrm{Te}$, Sci. Rep. 2 (2012) 726.

[64] B. Zhao, P. Cheng, H. Pan, S. Zhang, B. Wang, G. Wang, F. Xiu, F. Song, Weak Antilocalization in $\mathrm{Cd}_{3} \mathrm{As}_{2}$ Thin Films, Sci. Rep. 6 (2016) 22377.

[65] A. V. Matetskiy, N. V. Denisov, A. V. Zotov, A. A. Saranin, Weak Antilokalization at the Atomic-Scale Limit of Metal Film Thickness, Nano Lett. 19 (2019) 570-575. 